lesions \&c, although no glvcosuria was discoverable, and in which he thinks there wassufficient improvement in thelesions to warrant a more hopeful prognosis being taken of the disease than the available statistics would lead one to suppose. Sutherland-avenue, w.

\section{SIMULTANEOUS DISLOCATION OF BOTH SHOULDER.JOINTS.}

By T. W. J. Allen,

HONORARY SURGEON TO THE GRIMSHX HOSPITAL.

IN connexion with the accounts of simultaneous fracture of both clavicles, recently published in THE LANCET, I think the following case worth recording.

A young man, aged twenty four, works on the Fish Dock, driving a cart, and packing fish. Within the last four years he has from different causes dislocated the right shoulder four times and the left shoulder three times, and on each occasion came under my observation. Ten days ago I was called in toseehim, and found him suffering from a subcoracoid dislocation of both joints. He said that on getting hurriedly out of bed to assist an invalid brother he turned faint and fell, and upon recovering his senses found both his shoulders "out." I had no difficulty in reducing the deformity by the heel in each axilla in the usual way.

Great Grimsby.

\section{CASE OF TRISMUS NEONATORUM.}

BY J. C. O'Sullivan, L.R.C.P.E., \&c.

Ox the night of July 3 rd I was called to see the child of Mrs. H-, who gave it birth four days previously. The jaws were rigidly fixed and the finger could not be introduced into the mouth. There was a deep ridge on the forehead, giving the face an expression of frowning. The angles of the mouth were drawn outwards. The temperature was normal, and the umbilical cord had healed healthily at the place where it was divided. I told the patient's friends that tetanus was probably impending. The routine modes of treatment, warm baths, \&c., were ordered to be tried. Convulsions came on the following morning at $2 \mathrm{~A}$ M. These were strong, rigid, and continuous. The fingers were clenched on the palm, the back arched, abdomen upwards, and the bead thrown back. There was much lividity, and the convulsive movements occurred five or six times an hour. The child died this morning (July 5th). There was no defective sanitation or other recognisable cause to explain the disease. The mother has been, and continues to be, healthy.

Fast-street, Walworth, S.E.

\section{FIBROID TUMOUR OF THE CERVIX UTERI.}

\section{By Percy Boulton, M.D., M.R.C.P.Lond.,} PHYSICIAN TO THE SAMARITAN FREE HOSPITAL,

THE rarest position for a mural fibroid is in the cervix below the os internum, and the following is the report of a typical case which has recently been under my care.

F. C- married, aged thirty-six, had been suffering from severe hamorrhage almost continuously for six months, and when not bleeding had a copious discharge, with debility and backache. She had been seen by several practitioners who had told her she had a tumour, bnt a distinct diagnosis had not been arrived at. On exploration the vagina was found to be oceupied by a tumour, more or less oval in shape and as large as a gonse s egg. It clearly was not a polypus, as no encircling cervix could be felt, and the tumour first suggested to my mind a conplete inversion of the uterus. High up in front above the pubes, a slit-like depression like an ordinary button-hole from $\frac{1}{2}$ in. to $\frac{3}{4} \mathrm{in}$. in length could be felt. I thought this might be the os, but to clear up the idea of inversion, I passed my finger into the rectum when the diagnosis was at once made apparent, for the uterus could be distinctly felt above the tuuour, which was found to be entirely in the cervix By the bimanual process this was confirmed, though not so uninistakably as by rectal examination, as the patient was fat. I then dilated with my inger what I had supposed might be the os. The anterior lip was exceedingly thin and the posterior lip effaced by the turnour, so the finger passed backwards over its convex anterior surface. I made an incision with the cantery knife down the centre of the tumour, beginning at the os, and enucleated the growth, and the patient has made a good recovery.

The case is interesting because it is uncommon, but especially from a diagnostic point of view, for if the growth had been mistaken for a polypus, and it had been removed by the écraseur, Douglas' pouch would certainly have been opened; while if it had been treated as an inver-. sion, the attempts at reposition might have led to pelvic inflammation or other trouble.

Seymour-street, $\mathrm{W}$.

\section{de ettirtor}

\section{HOSPITAL PRACTICE, BRITISH AND FOREIGN.}

Nulla autem est alia pro certo noscendi via, nisi quamplurimas et mor bortm et dissectionum historias, tum aliorum tum proprias collecta habere, et inter se comparare.-MorgagNI De Sed. et Caus. Morb. lib. iv. Procmium

\section{CHARING-CROSS HOSPITAL.}

CALCULOUS PYELITIS ; RIGHT NEPHRO-LITHOTOMY ; PELVIC ABSCESS ; RECOVERY.

(Under the care of Mr. BELlamy.)

REPORTS of all cases requiring operation on the kidney are of the greatest clinical value, and an accurate record should be taken of every condition and symptom, for we are but on the borderland of perfection in kidney surgery. Hardly any two cases are alike, and we learn from each, either from error or success. We think the case here reported of peculiar interest. The extreme difficulty of the operation, a peritoneal wound (absolutely unavoidable), the immense pro trusion of bowel, and, as Mr. Bellamy suggested, a possible abnormal position of the organ, made the case a very unfavourable one. The subsequent pelvic abscess was possibly the result of the wound of the peritoneum, but, as will be seen from the notes, owing to the length of time after operation at which it appeared, this is doubtful. For the notes of the case we are indebted to Mr. Da Costa, surgical registrar.

T. LMarch 18th, 1890. Had always been well. Enjoyed good health as a boy until sixteen years of age, when he was struck. over the right loin, after which he was laid up in bed for ten days, for five days of which he suffered from hæmaturia. He recovered from this completely as far as he remembers, but had a slight return of hæmaturia eighteen months afterwards following unusual exertion. He was quite well until 1879, when he noticed a mucous deposit in his urine (in 1870 he had an attack of gonorrhoea, followed by swollen testicles; this attack lasted only ten days), which was ascribed by a surgeon to cystitis. He then went to Guy's Hospital, where he was treated in the wards for cystitis. He was under treatment for four months. The deposit has gradually been increasing and getting thicker. Four months ago he had bronchitis, and was then advised to wash out his bladder with boro-glyceride, a drachm to half a pint of water, twice daily. He did not derive any benefit from this. Four weeks ago he saw a surgeon, who sounded him for stone, but did not find any. Mother died of asthma when fifty. Father died of old age. All his brothers and sisters were heal thy, no relative dying either of cancer or phthisis. The patient is well nourished. Heart and lungs are healthy; pulse 68; temperature normal. Urine: $(\alpha)$ Frequency. Passes urine four or five times daily, not at all during the night. (b) Character of stream: Passes a fair-sized stream, with good impulse. (c) Pain: Has slight pain on passing urine, especially at the end of micturition. Stream does not stop suddenly ; with the first and last part of the stream urine comes away with a white turbidity. Patient has not passed any blond for the past twenty-four years. Examination of urine: Cloudy, and on standing yields considerable deposit; the odour is not offensive; sp. gr. 1012 ; slightly acid ; contains about one-sixth albumen. Under the microscope it contains a large quantity of pus. The patient has 